\title{
Inversion polymorphism and accumulation of lethals in selected lines of Drosophila melanogaster
}

\author{
J. ALBORNOZ* \& A. DOMÍNGUEZ \\ Departamento de Biologia Funcional, Area de Genética, Universidad de Oviedo, 33071 Oviedo, Spain
}

\begin{abstract}
Five long-term selected lines of Drosophila melanogaster were monitored for the presence of lethals and inversions on the third chromosome for a period of nearly 100 generations after the cessation of selection. The results provide an example of the action of inversions as a trap for genes with homozygous detrimental effects in small populations. Lines polymorphic for cosmopolitan inversions $\operatorname{In}(3 R) C$ and $\operatorname{In}(3 L) P$ maintain linked lethal and detrimental genes in a near-balanced system. Consideration of the high selection response attained despite inversion polymorphism leads to the conclusion that extreme responses to selection can be obtained without exploiting the potential from large genomic regions.
\end{abstract}

Keywords: artificial selection, Drosophila melanogaster, inversion polymorphism, lethal genes, Müller's ratchet, population genetics.

\section{Introduction}

Accumulation of detrimental alleles in artificially selected lines has been mainly studied from the point of view of the limits of response to selection. A limit of selection can be reached in spite of genetic variation for the selected trait when artificial selection is opposed by natural selection (Nicholas \& Robertson, 1980).

An extreme example of this occurs when artificial selection favours the heterozygous form of a recessive lethal. The frequency of such a lethal can then increase to values approaching a maximum of one-half in the selected individuals. As a consequence the probability of losing recessive detrimental alleles at other loci linked in disequilibrium to the first and therefore protected from natural selection, is reduced. This will occur whether or not these alleles affect the selected trait (Madalena \& Robertson, 1975). A progressive accumulation of detrimentals in coupling or in repulsion with the first will then ensue.

Experimental data on the accumulation of lethals in artificially selected lines of Drosophila have been documented on several occasions. Most work on this topic shows that one or more lethals have an effect on the selected trait (Clayton \& Robertson, 1957; Frankham et al., 1968; Madalena \& Robertson, 1975; Yoo, 1980;

*Correspondence.
García-Dorado \& López-Fanjul, 1983), even though in some cases their frequency was too high to be explained by their effect on the selected trait. On the other hand, there are some examples of accumulation of lethals (Skibinski, 1986; Domínguez et al., 1987; García-Dorado and López-Fanjul, 1987) that could not be accounted for by the action of artificial selection.

Most of the above-mentioned works do not take into account other phenomena of importance in finite populations such as meiotic drive or the suppression of recombination by chromosomal abnormalities. One of the effects of inbreeding is gene fixation in the homozygous state, but another effect may be, paradoxically, to permit the establishment of fixed heterozygosity. In small populations, inversions or other rearrangements suppressing recombination can act as a trap for detrimental alleles (Müller, 1964; Felsenstein, 1974; James, 1992). Chance fixation of detrimental mutations in haplotypes closed to recombination and subjected to genetic drift ('Müller's ratchet mechanism') can result in an increasing superiority of heterokaryotypes. Accordingly, heterozygosity in such regions becomes increasingly obligatory, and the return to a homozygous state becomes increasingly difficult, leading to a balanced system. This process appears to be responsible for a number of cases of permanent heterozygosity in a variety of species (Carson, 1967).

In previous experiments Domínguez et al. (1987) have found high frequencies of chromosome II and III 
lethals in long-term selected lines. Accumulation of lethals and detrimentals on chromosome II has been explained by its association with the Segregation Distorter complex (SD, Lyttle, 1991) together with drift and restricted recombination (Domínguez et al., 1993b). This paper describes the evolution of chromosome III lethals during a period of relaxation of nearly 100 generations, and provides evidence that they are kept stably in the lines because of their association with polymorphic inversions.

\section{Materials and methods}

Ac-27P, Ac-27S, S-27P, S-27S and N-21 are five longterm selected lines derived from a population caught in a wine cellar in 1976. They were selected for increased dorsocentral bristle number for 110 generations. At first, three lines were established: N-21, Ac-27 and S-27. Lines Ac-27S and Ac-27P were derived from the single selected line Ac-27 at generation 16. In the same way, lines S-27S and S-27P were derived from S-27 at generation 17 (for more details see Domínguez et al., 1987, 1993a). Since generation 110, the lines have been kept without selection in three bottles per line with 10 pairs per bottle per generation.

Before selection was stopped, Domínguez et al. (1987) found three different chromosome III lethals in samples of selected males at generation 107. Lethal $I I I_{I}$ was detected in line Ac-27S, lethal $I I_{2}$ in lines S-27S and S-27P and lethal $I I_{3}$ in line Ac-27P. One representative lethal chromosome from each allelic group was kept in stock balanced with the TM3 chromosome (for a full description of this and other special stocks see Lindsley \& Zimm, 1992).

Figure 1 shows the general mating procedure practised to test chromosomes III from the lines for lethals, inversions, fertility and viability. Lethals were scored by individual crosses between a random sample of males from every line and a $T M 3 / P r$ balanced stock.
One $\operatorname{Pr}$ male was picked up from each progeny and tested for lethals previously found by crossing with the appropriate lethal representative stock. Lethality of chromosomes lacking $\mathrm{III}_{1}, \mathrm{II}_{2}$ or $\mathrm{II}_{3}$ was tested in the offspring of $T M 3 \times T M 3$ crosses (G2 in Fig. 1). In every case a chromosome was classified as lethal when no wild-type individuals were recovered among at least 50 progeny of the appropriate mating. This arbitrary number yields a probability less than or equal to 0.08 of misclassifying as lethal a chromosome with a homozygous viability greater than or equal to 0.1 .

Inversions were scored by crossing $T M 3$ males from $\mathrm{G} 2$ with Canton $\mathrm{S}$ females. Salivary glands from thirdinstar larvae were dissected, squashed and orceinstained according to a standard protocol (Ashburner, 1989).

Meiotic drive was tested for by comparing the segregation ratio $(k)$ of lethal versus non-lethal chromosomes in heterozygous males and females. In essence, eight chromosomes were extracted from each individual in a sample of males and females and classified as lethal or non-lethal by progeny tasting. Hence individual genotypes were ascertained and $k$ values calculated for each heterozygote. This was accomplished as follows: a random sample of 30 males and 30 females from each line were individually crossed to the $T M 3 / P r$ stock and eight TM3 males, taken from each progeny, were crossed with the representative balanced stock of the lethal $I I I_{1}$ or $I I I_{2}$. When at least one of these last matings did not yield wild-type progeny, the tested specimen was classified as lethal heterozygote $\left(I I I_{i} / I I I_{i}^{+}\right)$. The $k$ value for each heterozygous G0 specimen was scored as the proportion of $I I I_{i} / T M 3$ males in his progeny. The mean $k$ value of $\mathrm{III}_{i} / \mathrm{III}_{i}^{+}$males compared to that of females, provided a test of distortion of segregation within the line.

Lethals were located by using the rucuca $(r u, h, t h$, $\left.s t, c u, s r, e^{s}, c a\right)$ and ruPrica $\left(r u, h, t h, s t, c u, s r, e^{s}, P r\right.$, ca) chromosomes (for a more detailed description see
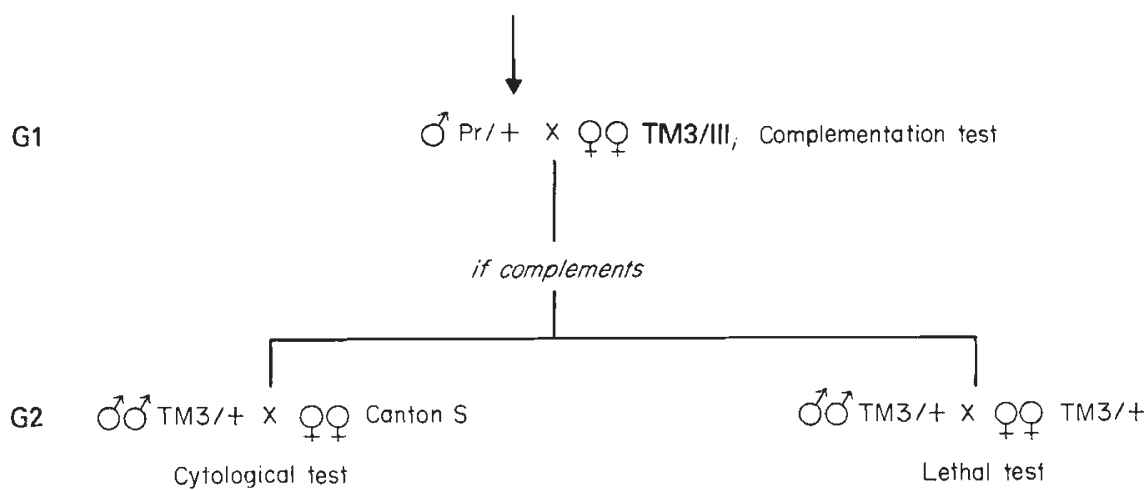

Fig. 1 General mating scheme to test chromosomes III for lethality and inversions. 
Lindsley \& Zimm, 1992). Males from the $I I I_{i} / T M 3$ representative stocks were crossed to rucuca females. $I I I_{i} /$ rucuca females from their progeny were crossed to ruPrica/TM3 males. Recombinants between the lethal and rucuca chromosomes were recognized when heterozygous with ruPrica and tested for lethality by crossing individually with females from the balanced stock from the corresponding lethal $\left(I I I_{i} / T M 3\right)$.

\section{Results}

The evolution of frequencies of lethals $\mathrm{II}_{1}$ and $\mathrm{II}_{2}$ in lines S-27S, S-27P and Ac-27S is shown in Table 1. They were maintained at frequencies near $1 / 3$ for a large number of generations. Lethal $\mathrm{II}_{3}$ was found at a frequency of 0.12 in line Ac-27P at generation 107, but it was not detected in successive tests.

Lethal $I I I_{I}$ was associated with the inversion $\operatorname{In}(3 L) P$ $(63 \mathrm{~B} 8-11 ; 72 \mathrm{E} 1-2)$. It is located in the left arm of chromosome III. No recombinants were found between ruсиса and the left arm of the chromosome bearing the representative copy of lethal $I I I_{l}$. All $I I I_{L^{-}}$ carrying chromosomes extracted from line Ac-27S at generations 135,170 and 185 bore the inversion, and all homozygotes for standard chromosomes were viable and fertile.

Table 2 shows the results of mapping the representative copy of lethal $I I I_{2}$. The results suggest a complex of at least two lethals, one located between the markers curled $(\mathrm{cu}, 50 \mathrm{cM})$ and stripe $(s r, 62 \mathrm{cM})$ and the other between ebony (e, $70.7 \mathrm{cM}$ ) and claret (ca, $100.7 \mathrm{cM})$. It is possible that there may be some other lethals between these two, but this method only allows detection of the two extremes. The recombinant class ++ $+s r e^{s} c a$ was heterogeneous because some chromosomes were recombinant between the marker $c u$ and the left lethal, and others between the lethal and the $s r$ marker. The same can be said for the $h$ st cu sr $e^{s}+$ class, but if there were another lethal between these two, for instance in the $s r-e^{s}$ region, it would not be detected because the $h$ st $\mathrm{cu} \mathrm{sr}++$ recombinants would bear the right-most lethal and the $t+++e^{s}$ $c a$ the left-most.

Two lethal recombinant chromosomes (hst cu sr e $e^{s}$ + and $\left.+++s r e^{s} c a\right)$ bearing the two extreme lethals of the complex were balanced with TM3 and crossed with all the $I I I_{2}$-bearing chromosomes extracted from lines S-27S and S-27P at generation 170. There was no complementation in any case, showing that all the $\mathrm{III}_{2}$-bearing chromosomes shared at least the two extreme elements of the $\mathrm{III}_{2}$ complex. Lines S-27S and S-27P were both polymorphic for inversion (3R)C (92D1-E1; 100F2-3). Lethal $\mathrm{III}_{2}$ was always found associated with the standard ordination, whereas all $\operatorname{In}(3 R) C$ chromosomes were lethal-free except one sampled from line S-27S at generation 185 . Homozygotes for non-lethal chromosomes were all fertile.

The two other lines were not polymorphic for chromosome III inversions. N-21 was homozygous for $\operatorname{In}(3 R) C$, and $\mathrm{Ac}-27 \mathrm{P}$ for the standard ordination. No third chromosome lethals were detected in either line at generations 135 and 170 .

Lethals $I I I_{I}$ in Ac-27S and $I I I_{2}$ in lines S-27 were not balanced by deleterious recessive genes with sizeable influences on viability. In lethal tests (Fig. 1) of generation 185,15 vials were set up, each with a pair of a virgin TM3 heterozygous female and a male. Offspring from eggs laid in the first 5 days were scored and compared with the $2: 1$ theoretical segregation by $\chi^{2}$ tests. Results departed significantly from expected $(P<0.001)$ in the three lines. The viability of homozygotes, calculated as the number of observed wild-type flies divided by the expected number, was larger than 1 in every case (Table 3), denoting that standard homozygotes from line Ac-27S and $\ln (3 R) C$ homozygotes from lines S-27 were more viable than the corresponding TM3 heterozygotes.

Table 4 shows mean $k$ scores for lethals $\mathrm{III}_{1}$ and $\mathrm{III}_{2}$ in heterozygous males and females. Errors are based on observed variances. Preferential transmission of lethals in males was tested for by comparing the $k$

Table 1 Frequencies of chromosome III lethals (number of tested individuals in parentheses)

\begin{tabular}{|c|c|c|c|c|c|c|c|c|}
\hline \multirow[b]{2}{*}{ Lethal } & \multirow[b]{2}{*}{ Line } & \multicolumn{7}{|c|}{ Generation } \\
\hline & & $107^{*}$ & 135 & 138 & 150 & 170 & 185 & $200^{*}$ \\
\hline$I I I_{I}$ & $\mathrm{Ac}-27 \mathrm{~S}$ & 0.28 & $0.07(28)$ & - & - & $0.42(19)$ & $0.32(34)$ & $0.25(57) \dagger$ \\
\hline $\mathrm{III}_{2}$ & $S-27 S$ & 0.17 & $0.31(29)$ & $0.38(58) \dagger$ & $0.28(60) \dagger$ & $0.43(58)$ & $0.23(30)$ & - \\
\hline $\mathrm{III}_{2}$ & $S-27 P$ & 0.14 & $0.30(30)$ & $0.39(60) \dagger$ & $0.36(57) \dagger$ & $0.32(55)$ & $0.33(30)$ & - \\
\hline
\end{tabular}

*Data from Domínguez et al., 1987.

†Scored from genotypic frequencies in meiotic drive tests. 
values yielded in males and females by means of onetailed Student's $t$-tests. In line S-27S the lethal $I I_{2}$ segregation ratio was significantly higher in males than in females. Though not significant, the same trend could be observed for line S-27P. If results from the two lines are considered jointly, preferential transmission of the lethal $\mathrm{II}_{2}$ in heterozygous males is significant at the $P=0.01$ level $\left(\chi_{8}^{2}=22.90\right)$. This result points to a distortion of segregation similar to that of the $S D$ complex.

In most segregation distorter systems, preferential transmission takes place by the interaction between a

Table 2 Localization of lethal $\mathrm{II}_{2}$

\begin{tabular}{|c|c|c|c|c|c|c|c|}
\hline \multicolumn{6}{|c|}{ Recombinant chromosomes } & \multirow{2}{*}{ Non-lethal } & \multirow{2}{*}{$\frac{\text { Lethal }}{0}$} \\
\hline$h$ & $s t$ & $c u$ & $s r$ & $e^{s}$ & $c a$ & & \\
\hline+ & $s t$ & $c u$ & $s r$ & $e^{s}$ & $c a$ & 13 & 0 \\
\hline+ & + & $\mathrm{cu}$ & $s r$ & $e^{s}$ & $c a$ & 10 & 0 \\
\hline+ & + & + & $s r$ & $e^{s}$ & $c a$ & 4 & 2 \\
\hline+ & + & + & + & $e^{s}$ & $\mathrm{ca}$ & 0 & 7 \\
\hline+ & + & + & + & + & $c a$ & 0 & 13 \\
\hline+ & + & + & + & + & + & 0 & 13 \\
\hline$h$ & + & + & + & + & + & 0 & 13 \\
\hline$h$ & $s t$ & + & + & + & + & 0 & 13 \\
\hline$h$ & $s t$ & $c u$ & + & + & + & 0 & 10 \\
\hline$h$ & $s t$ & $c u$ & $s r$ & + & + & 0 & 7 \\
\hline$h$ & $s t$ & $c u$ & $s r$ & $e^{s}$ & + & 6 & 6 \\
\hline
\end{tabular}

Table 3 Viability of homozygotes for non-lethal chromosomes relative to that of TM3 heterozygotes (see text for more details)

\begin{tabular}{lcrcc}
\hline Line & $+/+$ & $+/ T M 3$ & $\chi^{2}$ & Viability of $+/+$ \\
\hline S-27S & 932 & 1328 & $63.56^{*}$ & 1.24 \\
S-27P & 793 & 1255 & $26.75^{*}$ & 1.16 \\
Ac-27S & 841 & 1454 & $11.32^{*}$ & 1.10 \\
\hline
\end{tabular}

${ }^{*} P \leqslant 0.001$. distorter locus in the drive chromosome and a target locus in its homologue (Lyttle, 1991). Target alleles have different degrees of sensitivity to the distorter, and sensitive alleles are abundant in populations. To test further the possibility of preferential transmission of lethal $\mathrm{III}_{2}$, we have tested the transmission ratio of $\mathrm{III}_{2}$-bearing chromosomes against several recessivemarked chromosomes III from laboratory strains (rucuca, ebony, sepia and scarlet) and the cinnabar brown strain sensitive to Segregation distorter $(S d)$, but we failed to find any distortion. Tests for sensitivity of chromosomes III from lines Ac-27S, Ac-27P and N-21 to recessive-marked $\mathrm{III}_{2}$-bearing chromosomes also provided negative results. It thus seems probable that the observed differences in transmission between sexes were actually due to differences in viability between the male progeny of the reciprocal crosses that could be attributed to the different genetic constitution of the $\mathrm{X}$ chromosome.

\section{Discussion}

The stability of the polymorphism after relaxation of selection proves that it is not maintained by artificial selection. This corroborates the assumptions of Domínguez et al. (1987) based on the lack of effect of lethals on the selected trait. Lethals on chromosome III have been submitted to forces different from artificial selection. However, in contrast to lethals on chromosome II (Domínguez et al., 1993b), preferential transmission cannot account for their maintenance. Although it was statistically significant in lines S, failure in the search for sensitive chromosomes points to the possibility that it was an artefact.

The selection coefficient necessary to maintain a balanced polymorphism can be obtained from the equation $\hat{q}=s_{1} /\left(s_{1}+s_{2}\right)$. Lethals in this study fluctuated around frequencies near $1 / 3$ and, therefore, the selection coefficient against non-lethal chromosomes $\left(s_{1}\right)$ must be around 0.5 . Nevertheless, they do not bear

Table 4 Segregation ratios of lethal versus non-lethal bearing chromosomes $(k)$ from heterozygotes (number of tested heterozygotes in parentheses)

\begin{tabular}{lcccccc}
\hline Lethal & Line & Generation & $k$ Males & $k$ Females & d.f. & $t$ \\
\hline$I I I_{I}$ & Ac-27S & 200 & $0.46 \pm 0.04(14)$ & $0.49 \pm 0.04(15)$ & 27 & 0.49 \\
$I I I_{2}$ & S-27S & 138 & $0.52 \pm 0.04(21)$ & $0.43 \pm 0.03(23)$ & 42 & $1.87^{*}$ \\
& & 150 & $0.50 \pm 0.04(18)$ & $0.40 \pm 0.04(16)$ & 32 & $1.76^{*}$ \\
$I I I_{2}$ & \multirow{2}{*}{$\mathrm{S}-27 \mathrm{P}$} & 138 & $0.46 \pm 0.03(24)$ & $0.41 \pm 0.03(23)$ & 45 & 1.22 \\
& & 150 & $0.50 \pm 0.03(20)$ & $0.43 \pm 0.03(21)$ & 39 & 1.65 \\
\hline
\end{tabular}

$* P \leqslant 0.05$. 
genes with clear-cut negative effects on viability nor fertility. The genetic load of $I I I_{l}$ and $I I I_{2}$ lethals must be counteracted by accumulation on the opposite chromosomes of genes with negative effects on other components of fitness, probably prezygotic ones such as fecundity or sexual activity.

Our results can be interpreted on the basis of Müller's (1964) 'ratchet mechanism'. Polymorphism for inversions and small population size must be responsible for the accumulation of detrimentals. Chance fixation of detrimental alleles in haplotypes closed to recombination can increase the heterokaryotype advantage (Ohta, 1971; Felsenstein, 1974; James, 1992) and finally lead to a balanced system. The process will be favoured if heterokaryotypes initially show a selective advantage large enough to maintain the polymorphism in the face of drift, which is likely because overdominance is very frequently observed for paracentric inversions in natural populations (Sperlich \& Pfreim, 1986).

Overdominance of inversions can, in turn, be interpreted as a consequence of lack of recombination (Ohta, 1971). Coincident occurrence of the $\mathrm{III}_{2}$ complex in two lines suggests that the polymorphism for $\operatorname{In}(3 R) C$ in the base population was maintained by associative overdominance. Inoue \& Watanabe (1992) showed that natural populations must be considered as sets of divided or semidivided small populations. In such subpopulations inversion polymorphism is maintained by heterokaryotype advantage, and is destroyed when inversions from different subpopulations recombine. Although they interpret their results on the basis of coadaptation, the same would be expected if chromosomal heterosis were due to deleterious recessive genes. The small size of such subpopulations would favour the ratchet mechanism.

We have no similar data to decide whether the elements involved in the balance of $\operatorname{In}(3 L) P$ came from the base population, but the persistence of the polymorphism in the face of artificial selection and drive should require strong balancing in the early stages of artificial selection. On the other hand, some data such as the loss of lethal $I I I_{3}$ in line Ac-27P and the variety of associations between $\operatorname{In}(2 L) t$, elements of the $S D$ complex and detrimental genes found by Domínguez et al. (1993b) in chromosome II of the lines Ac suggest that some associations had been established throughout the selection and relaxation processes.

Some cases of lethal polymorphism associated with inversions in natural populations (Coyne et al., 1991) and selected lines (García-Dorado \& López-Fanjul, 1987) can also be explained on the basis of the ratchet mechanism, but most other cases of accumulation of lethals in artificially selected lines have not been investigated for chromosomal abnormalities.
Table 5 Mean number of dorsocentral bristles in females and chromosome sequences found in the lines under study (ST = standard ordination)

\begin{tabular}{|c|c|c|c|}
\hline \multirow[b]{2}{*}{ Line } & \multirow{2}{*}{$\begin{array}{c}\text { No. of dorsocentral } \\
\text { bristles* }\end{array}$} & \multicolumn{2}{|c|}{$\begin{array}{c}\text { Types of chromosome } \\
\text { sequence }\end{array}$} \\
\hline & & $\mathrm{II}_{\dagger}^{\dagger}$ & III \\
\hline$A c-27 S$ & $16.9 \pm 0.5$ & $\ln (2 L) t+S T$ & $\operatorname{In}(3 L) P+S T$ \\
\hline$A c-27 P$ & $16.5 \pm 0.6$ & $\operatorname{In}(2 L) t+S T$ & $S T$ \\
\hline S-27S & $38.4 \pm 1.0$ & $S T$ & $\ln (3 R) C+S T$ \\
\hline$S-27 P$ & $36.8 \pm 1.1$ & $S T$ & $\ln (3 R) C+S T$ \\
\hline $\mathrm{N}-21$ & $35.6 \pm 1.3$ & $\operatorname{In}(2 L) t+S T$ & $\operatorname{In}(3 R) C$ \\
\hline
\end{tabular}

*Data from Domínguez et al. (1993a).

$\dagger$ Data from Domínguez et al. (1993b).

Finally, it is interesting to note the high degree of polymorphism found in these lines despite the long and successful selection process to which they were subjected (Table 5). The three lines with the higher selected phenotype (S-27S, S-27P and N-21) seem to share the same selected alleles distributed among the three major chromosomes (Domínguez et al., 1993a), but they have different inversion contents. It is thus clear that inversions were independent of selection response. The same can also be deduced from the fact that lethals in these lines had no influence on the selected trait (Domínguez et al., 1987). As most lethals were linked to inversions, neither inversion has any influence on the number of bristles.

In consequence the extreme phenotypes attained (even more than eight times the normal number of bristles, in lines S-27 and N-21) have been achieved without exploiting the potential from large genomic regions that had yielded to forces other than artificial selection. These results agree with theories relating selection response to a small number of genes with large effect (Thompson, 1975) and with recent experimentation on the distribution of effects of spontaneous mutations on quantitative traits denoting the presence of major genes (Santiago et al., 1992; López \& LópezFanjul, 1993).

\section{References}

Ashburner, M. 1989. Drosophila, a Laboratory Manual. Cold Spring Harbor Laboratory, Cold Spring Harbor, New York.

CARSON, H. L. 1967. Permanent heterozygosity. In: Dobzhansky, T. H., Hecht, W. M. and Steere, C. (eds) Evolutionary Biology, vol. 1, pp. 143-168. Meredith, New York. 
CLAYTON, G. A. AND ROBERTSON, A. 1957. An experimental check on quantitative genetical theory. The long-term effect of selection. J. Genet., 55, 152-170.

COYNE, J. A., AULARD, S. AND BERRY, A. 1991. Lack of underdominance in a naturally occurring pericentric inversion in Drosophila melanogaster and its implications for chromosome evolution. Genetics, 129, 791-802.

DomíngueZ, A., Albornoz, J. AND SANTIAgo, E. 1987. Analysis of lethals in selected lines of Drosophila melanogaster. Theor. Appl. Genet., 74, 409-413.

DOMínguez, A., Albornoz, J., SANTIAGo, E. AND GUTIÉRREZ, A. 1993a. Chromosomal analysis of Drosophila melanogaster long-term selected lines. J. Hered., 84, 63-66.

DOMínGUEZ, A., SANTIAGO, E., ALBORNOZ, J. AND GUTIÉRREZ, A. 1993b. The segregation distorter (SD) complex and the accumulation of deleterious genes in laboratory strains of Drosophila melanogaster. Theor. Appl. Genet., 87, 479-486.

FELSENSTEIN, J. 1974. The evolutionary advantage of recombination. Genetics, 78, 737-756.

FRANKHAM, R., JONES, L. P. AND BARKER, J. S. F. 1968. The effects of population size and selection intensity in selection for a quantitative character in Drosophila melanogaster. III. Analyses of the lines. Genet. Res., 12, 267-283.

GARCIA-DORADO, A. AND LOPEZ-FANJUL, C. 1983. Accumulation of lethals in highly selected lines of Drosophila melanogaster. Theor. Appl. Genet., 66, 221-223.

GARCIA-DORADO, A. AND LOPEZ-FANJUL, C. 1987. Balanced polymorphism at the selection limit in Drosophila melanogaster. J. Hered., 78, 110-111.

INOUE, Y. AND WATANABE, T. K. 1992. Chromosomal polymorphisms in isofemale lines and cage populations of Drosophila melanogaster. Evolution, 46, 797-806.

JAMES, S. H. 1992. Inbreeding, self-fertilization, lethal genes and genomic coalescence. Heredity, 68, 449-456.
LINDSLEY, D. L. AND ZIMM, G. G. 1992. The Genome of Drosophila melanogaster. Academic Press, New York.

LOPEZ, M. A. AND LOPEZ-FANJUL, C. 1993. Spontaneous mutation for a quantitative trait in Drosophila melanogaster. II. Distribution of mutant effects on the trait and fitness. Genet. Res., 61, 117-126.

Lyttle, t. w. 1991. Segregation distorters. Annu. Rev. Genet., 25, 511-557.

MADAlenA, F. E. AND ROBERTSON, A. 1975. Population structure in artificial selection: studies with Drosophila melanogaster. Genet. Res., 24, 113-126.

MÜLlER, H. J. 1964. The relation of recombination to mutational advance. Mutat. Res., 43, 165-229.

NICHOLAS, F. W. AND ROBERTSON, A. 1980. The conflict between natural and artificial selection in finite populations. Theor. Appl. Genet., 56, 57-64.

OHTA, T. 1971. Associative overdominance caused by linked detrimental mutations. Genet. Res., 18, 277-286.

SANTIAGO, E., ALBORNOZ, J., DOMÍNGUEZ, A., TORO, M. A. AND LOPEZ-FANJUL, C. 1992. The distribution of effects of spontaneous mutations on quantitative traits and fitness in Drosophila melanogaster. Genetics, 132, 771-781.

SKIBINSKI, D. O. F. 1986. Study of lethals in selection lines in Drosophila melanogaster. J. Hered., 77, 31-34.

SPERLICH, D. AND PFREIM, P. 1986. Chromosomal polymorphisms in natural and experimental populations. In: Ashburner, M., Carson, H. L. and Thompson, J. N., Jr (eds) The Genetics and Biology of Drosophila, vol. 3e, pp. 257-309. Academic Press, New York.

THOMPSON, J. N., Jr. 1975. Quantitative variation and gene number. Nature, 258, 665-668.

YOO, B. H. 1980. Long-term selection for a quantitative character in large replicate populations of Drosophila melanogaster. II. Lethals and visible mutants with large effects. Genet. Res., 35, 19-31. 